\title{
Tricuspid valve repair: Chordae transposition of the entire posterior leaflet for extensive anterior leaflet prolapse
}

Masanori Takamatsu, MD, Takashi Hirotani, MD, Satoshi Ohtsubo, MD, and Shigeyuki Takeuchi, MD, Tokyo, Japan

\author{
From the Department of Cardiovascular Surgery, Tokyo Saiseikai Central Hospital, Minato-Ku, Tokyo, Japan. \\ Disclosures: Authors have nothing to disclose with regard to commercial support. \\ Received for publication Feb 2, 2018; revisions received March 14, 2018; accepted for publication March 20, \\ 2018; available ahead of print April 22, 2018. \\ Address for reprints: Masanori Takamatsu, MD, Department of Cardiovascular Surgery, Tokyo Saiseikai Central \\ Hospital, 1-4-7 Mita, Minato-Ku, Tokyo 108-0073, Japan (E-mail: cvstaka@ hotmail.co.jp). \\ J Thorac Cardiovasc Surg 2018;156:655-7 \\ $0022-5223 / \$ 36.00$ \\ Copyright (C) 2018 by The American Association for Thoracic Surgery \\ https://doi.org/10.1016/j.jtcvs.2018.03.102
}

- Video clip is available online.

We herein report tricuspid valve repair for tricuspid valve regurgitation (TR) by transposing the entire posterior leaflet onto the flail anterior leaflet. The institutional review board approved the reporting of this case. The patient was a 46-year-old man who had been a drug addict in his late 20s. He had no history of any accident or blunt trauma. In a detailed examination for general fatigue 7 years earlier, he had been found to have severe TR and atrial fibrillation. He was admitted to our hospital due to worsening dyspnea under medication. Chest radiograph showed that the right atrium and right ventricle were enlarged, and the cardiothoracic ratio was $70 \%$. Two-dimensional echocardiography showed dilatation of the right atrium, right ventricle, and tricuspid valve annulus. Doppler echocardiography detected severe TR caused by a flail anterior leaflet (Video 1). He was referred for operation because of progressive symptoms.

The tricuspid valve was exposed under the arrested condition with cold cardioplegia under cardiopulmonary bypass. The chordae tendineae of the right two thirds of the anterior leaflet were ruptured (Figures 1, A, and 2, A). The entire posterior leaflet was sutured to the free margin of the flail anterior leaflet with separated 5-0 monofilament stitches (Figures 1, B, and 2, B). The relatively large posterior leaflet could be used to completely reconstruct the right two-third anterior leaflet. The posterior leaflet was completely detached from its annulus. The posterior leaflet annulus was plicated by pledgeted 2-0 polyester

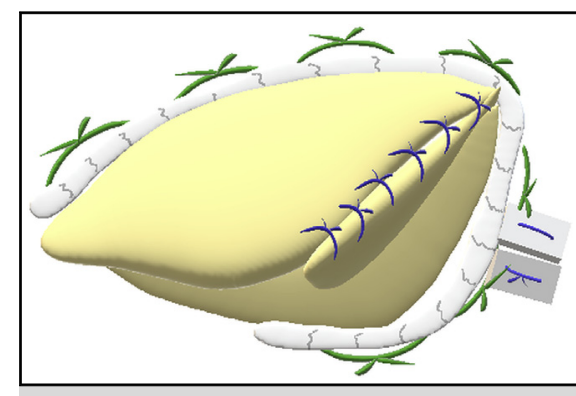

Tricuspid valve repair: Transposition of the posterior leaflet, Kay, and ring annuloplasty.

\section{Central Message}

We herein report a case of tricuspid valve repair with chordae transposition of the entire posterior leaflet onto the flail anterior leaflet's margin, suture bicuspidization, and ring annuloplasty.

See Editorial Commentary page 658.

suture (modified Kay annuloplasty; Figures 1, C, and 2, $C$ ). Injecting saline into the right ventricle revealed only minimal residual regurgitation from the anteroseptal commissure. A size 30-mm Carpentier-Edwards classic annuloplasty ring (Edwards Lifesciences, Irvine, Calif) was implanted to stabilize the repair and prevent further annular dilatation (Figures 1, D, and 2,D).

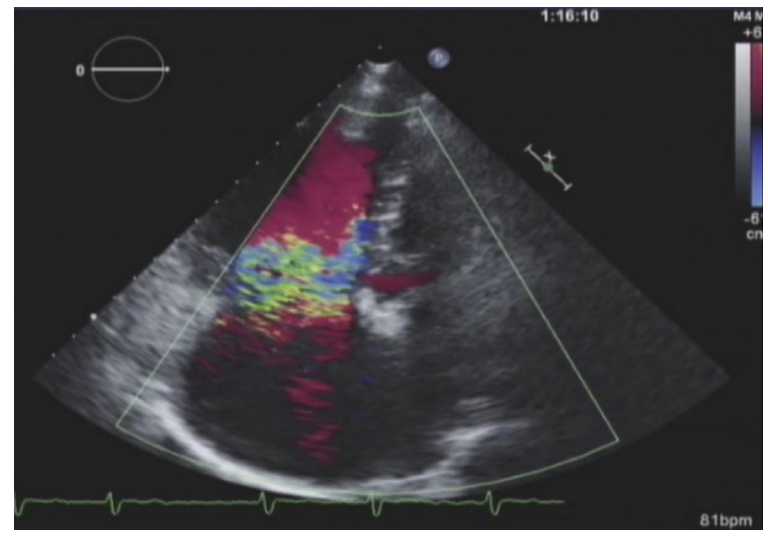

VIDEO 1. Preoperative, intraoperative, and postoperative echocardiography. Video available at: https://www.jtcvsonline.org/article/S00225223(18)30883-3/fulltext. 

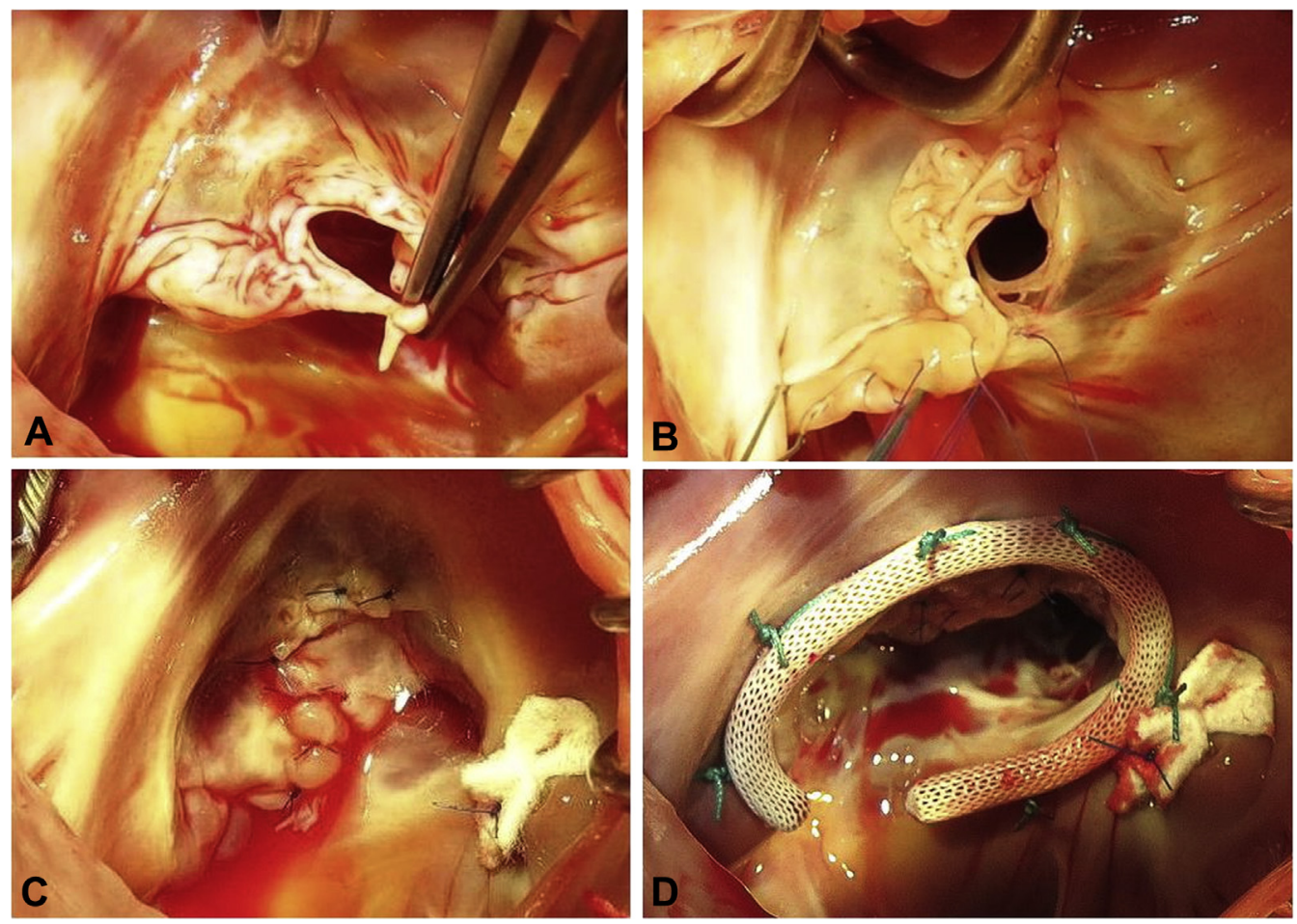

FIGURE 1. Photographs of tricuspid valve repair. A, Anterior tricuspid leaflet prolapse due to ruptured chordae tendineae. B, Chordae transposition with the entire posterior leaflet. C, A saline injection test revealed only minimal residual regurgitation after the posterior leaflet annulus was plicated. D, Insertion of the annuloplasty ring.

The operative course was uneventful, and the patient's symptoms were improved. One month after the surgery, follow-up echocardiography showed $1+$ TR due to slight tethering of the septal leaflet and no transvalvular gradient with good motion of the anterior leaflet (Video 1). At 1-year postsurgery, the patient remains in good health, and chest radiograph has shown a marked improvement of cardiomegaly with a cardiothoracic ratio of $55 \%$.

\section{COMMENT}

Compared with functional TR, TR secondary to ruptured chordae is rare and complex. Although tricuspid valve replacement might have been performed for complex TR, tricuspid valve repair might be preferable because the clinical outcome of tricuspid valve replacement is reportedly poor. ${ }^{1}$ In mitral valve repair, transposition of the posterior chordae for prolapse of the anterior leaflet seems to be an efficient technique. ${ }^{2}$ However, no report has described the tricuspid valve repair via leaflet transposition except for the acute or subacute TR caused by blunt trauma. ${ }^{3-5}$

In the present case, we selected the leaflet transposition technique for chronic TR due to ruptured chordae with the severely enlarged right ventricle. Chordae transposition of the entire leaflet might have some advantages compared with the repair technique using artificial chordae for TR with the severely enlarged right ventricle. First, leaflet transposition technique is quite a simple technique in which the margin of one leaflet has only to be sutured to the margin of another adjacent leaflet. There is no need to adjust the length of chordae or to resect part of the valve specially. Second, in cases of chronic TR with enlarged right ventricle, it is often difficult to adjust the length of the artificial chordae suitably for the systolic phase under arrested conditions. Third, tricuspid valve repair with the artificial chordae might fail to the recurrent TR after the remodeling of the large right ventricle because the adjusted artificial chorale in the severely enlarged right ventricle might become too long for the remodeled smaller right ventricle.

The detached area of the donor leaflet should be plicated as a modified Kay annuloplasty. In the present case, we added ring annuloplasty to reinforce the suture line. Although postoperative echocardiography showed $1+$ TR due to slight tethering of the septal leaflet, it might have been decreased by right heart remodeling, as the right ventricle volume was reduced after tricuspid valve repair. We herein reported chordae transposition of the entire posterior leaflet with modified Kay annuloplasty and ring annuloplasty for extensive anterior leaflet prolapse. 
A
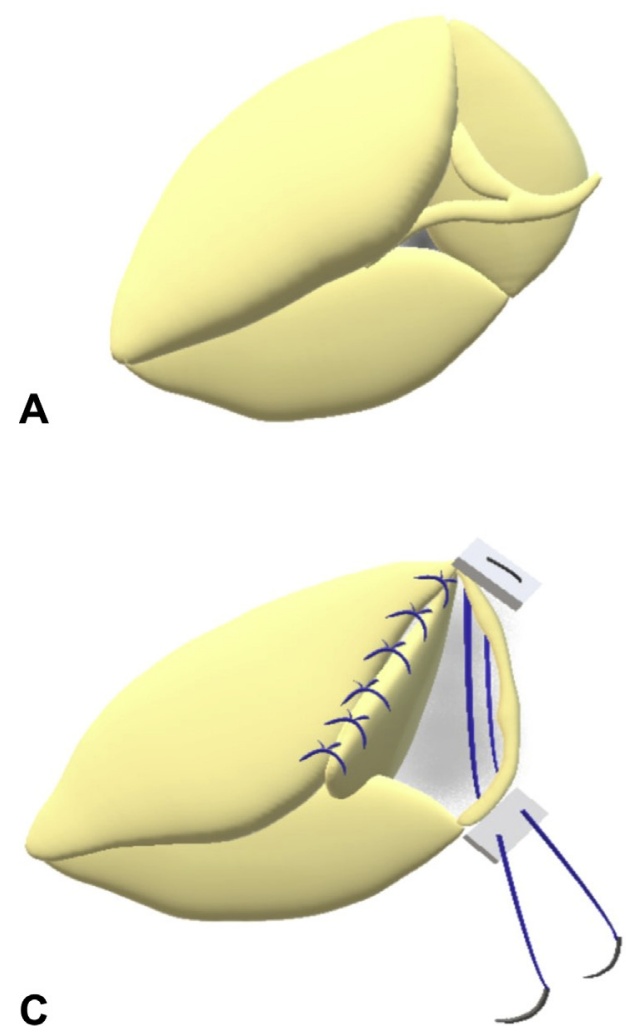

B
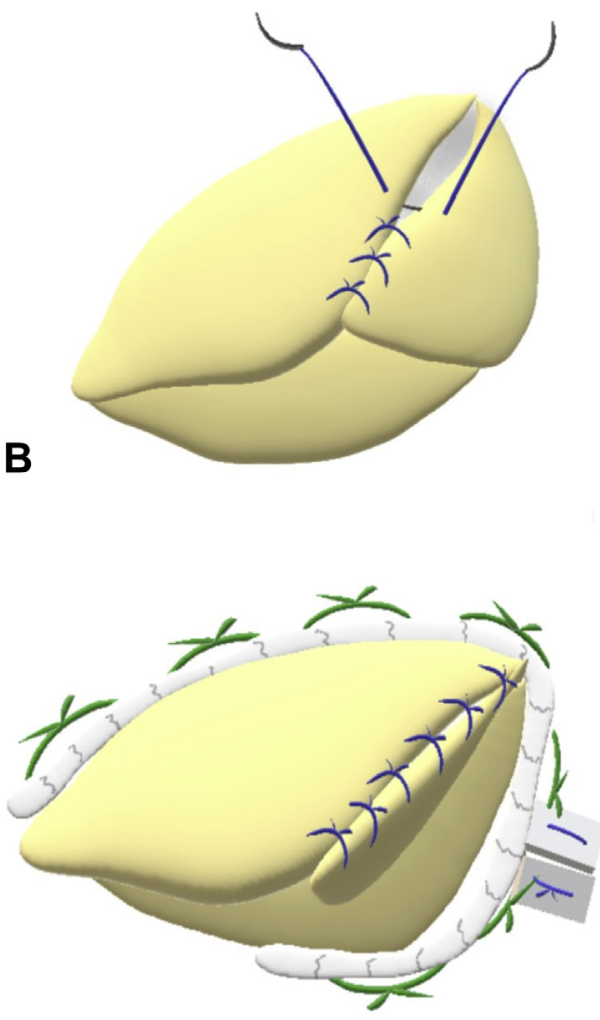

D

FIGURE 2. A schematic illustration of tricuspid valve repair. A, Ruptured chordae tendineae of the anterior tricuspid valve. B, Separated 5-0 monofilament stitches were applied to the posterior and anterior leaflets. C, The posterior leaflet annulus was plicated by pledgeted 2-0 polyester sutures after the posterior leaflet was detached. D, Insertion of the annuloplasty ring.

\section{References}

1. Scully HE, Armstrong CS. Tricuspid valve replacement. Fifteen years of experience with mechanical prostheses and bioprostheses. J Thorac Cardiovasc Surg. 1995;109:1035-41.

2. Carpentier A. Cardiac valve surgery - the "French correction." J Thorac Cardiovasc Surg. 1983;86:323-37.
3. Kalangos A, Baldovinos A, Sezerman O, Faidutti B. Tricuspid valve repair by septal or posterior leaflet transposition. Ann Thorac Surg. 1995;60:1807-9.

4. Turkoz R, Gulcan O, Atalay H, Uguz E. Surgical repair of tricuspid valve regurgitation caused by blunt thoracic trauma. J Trauma. 2007;60:e7-9.

5. Chan V, Grisoli D, Ruel M, Veinot J, Mesana T. Surgical approach to repair of ruptured chordae tendineae causing tricuspid regurgitation. J Thorac Cardiovasc Surg. 2009;137:e30-2. 